\title{
EL ENFOQUE FINANCIERO VS. EL ENFOQUE SOCIAL DEL MICROCRÉDITO. UN ANÁLISIS COMPARATIVO MUNDIAL
}

\author{
POR \\ Gemma CAIRÓ I CÉSPEDES ${ }^{1} \mathrm{y}$ \\ Luz Karime GÓMEZ GONZÁLEZ ${ }^{2}$
}

\section{RESUMEN}

La oferta del microcrédito por parte de las instituciones microfinancieras distingue dos enfoques, el llamado "alivio de la pobreza" y el de "autosostenibilidad financiera". En este trabajo se hace una comparativa mundial de cuatro regiones de países en vías de desarrollo con el fin de identificar bajo qué enfoque la población accede al microcrédito y a su vez verificar si existe un trade off entre ambos enfoques. Para su contrastación se han utilizado diez indicadores financieros y sociales clasificados en dos categorías, la sostenibilidad financiera y el alcance (nivel de pobreza). Los resultados obtenidos concluyen que el modelo financiero se presenta con más notoriedad en las regiones de América Latina y el Caribe y Oriente Medio/África del Norte mientras que en África prevalece el modelo social y en la región de Asia Meridional se aprecia un equilibrio entre ambos enfoques. Igualmente, se constata la contribución al alivio de la pobreza cuando el acceso del microcrédito se dirige mayoritariamente a la mujer.

Palabras clave: microcrédito, pobreza, sostenibilidad financiera, desarrollo.

Claves Econlit: I30, O16, O57, G21.

${ }^{1}$ Universitat de Barcelona. Dirección de correo electrónico: gcairo@ub.edu

${ }^{2}$ Universitat de Barcelona. Dirección de correo electrónico: karime513@ @otmail.com

REVESCO No 118 - Segundo Cuatrimestre 2015 - ISSN: 1885-8031 - www.ucm.es/info/revesco

http://dx.doi.org/10.5209/rev_REVE.2015.n118.49062

Fecha de recepción: 01/07/2014

Fecha de aceptación: 27/11/2014 


\title{
THE FINANCIAL VS. THE SOCIAL APPROACH OF MICROFINANCE. A COMPARATIVE GLOBAL ANALYSIS
}

\begin{abstract}
The supply of microcredit by microfinance institutions distinguishes two approaches, one called "poverty alleviation" and other "financial self-sustainability". In this study it is developed a global comparative in four regions of developing countries in order to recognize the approach to which the population get microcredits, an also to check if there is any trade off between both approaches. We've used ten financial and social indicators organized into two categories: financial sustainability and poverty's scope. The results show that in Latin America and the Caribbean and Middle East/North Africa is presented with more visibility the financial approach while in Africa the social approach prevails, and in the case of South Asia it is found that there is a balance between the two approaches. In addition it was discovered that the expansion of women's access to microcredit favors to the reduction of poverty.
\end{abstract}

Keywords: microcredit, poverty, financial sustainability, development.

\section{INTRODUCCIÓN}

La creciente expansión y desarrollo a nivel mundial del microcrédito en las últimas décadas parece indicar que éste se ha consolidado y que puede convertirse en una buena herramienta para cumplir el objetivo originario para el cual fue diseñado, facilitar el acceso a los recursos financieros a la población más pobre a fin de mejorar su situación socioeconómica. De hecho ésta es seguramente la única herramienta financiera no pública cuyo objetivo esté vinculado al alivio de la pobreza, lo que, desde la disciplina económica y más específicamente desde el campo de la economía del desarrollo, convierte el microcrédito en un interesante objeto de estudio.

Uno de los temas que más ha desarrollado la literatura económica sobre la temática del microcrédito ha sido la identificación de las diferentes tipologías de instituciones microfinancieras, y más concretamente, sobre el "enfoque" particular por el que opta una determinada entidad. A nivel teórico se han descrito dos grandes enfoques que priman en la actividad del sector microfinanciero. Uno de ellos es aquel cuyo objetivo principal es la "autosostenibilidad financiera" centrado por tanto en el desempeño de la eficiencia y la productividad de la entidad. El segundo sería aquel cuya orientación descansaría más 
netamente en el "alivio de la pobreza" como leit motiv de la entidad. Ambos enfoques, a nivel teórico, se desarrollan aparentemente como alternativos el uno del otro, de manera que a priori existiría un trade off entre ambos, es decir, entre por un lado perseguir la sostenibilidad financiera y por otro orientar la actividad hacia la reducción de la pobreza, lo que rechazaría una posible complementariedad entre ambos.

El objetivo de este trabajo es justamente contrastar esta hipótesis a nivel empírico, de manera que para un conjunto representativo de países del mundo en desarrollo, agrupados por regiones, se pretende verificar si existen de forma diferenciada modelos de microcrédito asentados en uno de estos dos enfoques, y a su vez, contrastar si pueden diferenciarse a nivel regional los mencionados modelos de microcrédito para concluir si efectivamente existe (entre las regiones escogidas) esta incompatibilidad o trade off entre el modelo financiero (autosostenibilidad) y el modelo social (pobreza), o si, contrariamente, en algunas de las regiones muestran un modelo real donde se consiguen ambos objetivos a la vez. Para ello, partiendo de dos grandes categorías analíticas que nos referencian a tales enfoques, la sostenibilidad y el alcance, se obtienen unos indicadores financieros y sociales universales y homogéneos a nivel internacional que nos permiten identificar una tipología dentro el sector microfinanciero en cada una de las regiones estudiadas, América Latina, África, Asia Meridional y Oriente Medio/Norte de África.

Especial mención toma la perspectiva de género en este trabajo, que si bien no es el objetivo principal del mismo, sí se aborda aquí hasta qué punto el acceso de la mujer al microcrédito es uno de los rasgos destacados de algunos de los dos modelos mencionados. El hecho de que las mujeres signifiquen una proporción mayor de pobres que los hombres y el específico impacto del trabajo (productivo y reproductivo) de la mujer en términos de desarrollo y alivio de la pobreza nos ha conducido a incorporar de forma colateral la dimensión de género en el estudio de los modelos de microcrédito que aquí se plantea, teniendo en cuenta la doble particularidad en la concepción del mismo, a saber, la orientación del microcrédito a los más pobres entre los pobres y su pretendido impacto sobre el desarrollo socioeconómico.

Este trabajo consta, además de esta breve introducción, de tres secciones. En la segunda sección se abordan las aportaciones teóricas sobre el microcrédito en especial referencia a la caracterización de los dos principales enfoques sobre los que se asientan las entidades microfinancieras así como a un breve análisis de los paradigmas del microcrédito 
desde la perspectiva de género. En la tercera sección se desarrolla el análisis empírico donde se elaboran los diferentes indicadores financieros y económicos desde una dimensión regional, para observar la existencia de diferentes modelos regionales de microcrédito, y las particularidades que se observan en cada uno de ellos. Y para concluir, en la última sección, se apuntan los principales resultados obtenidos para verificar si efectivamente los datos avalan la diferenciación de dos modelos de microcrédito a nivel mundial confirmándose el planteamiento teórico de los dos enfoques, y si además, estos dos modelos son excluyentes.

\section{MARCO TEÓRICO DEL MICROCRÉDITO: ENFOQUES FINANCIERO Y SOCIAL}

La definición adoptada sobre el microcrédito en la Primera Conferencia Internacional sobre Microfinanzas ${ }^{3}$ hace referencia a que "los microcréditos son programas de concesión de pequeños créditos a los más necesitados de entre los pobres para que éstos puedan poner en marcha pequeños negocios que generen ingresos con los que mejorar su nivel de vida y el de sus familias" (Cumbre de Microcrédito, 1997). A pesar de esta reciente formalización conceptual e institucional, el microcrédito tiene sus orígenes en Bangladesh a comienzos del siglo XX si bien se dio a conocer mundialmente en los años setenta por Muhammad Yunus a través de su institución microfinanciera el Grameen Bank. El profesor Yunus comenzó su lucha contra la pobreza a principios de los años 70s durante la hambruna que azotó a la población de Bangladesh tras independizarse de Pakistán (Yunus, 2006). De esta experiencia se pudo observar como los microcréditos, especialmente los concedidos a mujeres, basados en grupos solidarios de responsabilidad recíproca, consiguieron aliviar las dificultades económicas de muchas familias, lo que llevó a replicar el modelo en los cinco continentes.

A lo largo del desarrollo del microcrédito han ido emergiendo una serie de mitos sobre aspectos que hacen referencia a puntos centrales del mismo, como son la lógica de su concepción, la garantía de devolución del crédito, su vinculación con la pobreza y los beneficios de la instituciones microfinancieras (Armendáriz y Murdoch, 2007). En relación al primero de ellos, cabe mencionar que si bien en un principio se percibía el microcrédito casi exclusivamente con el otorgamiento de créditos, se ha ido ampliando su concepción como herramienta que también está ligada a otros productos financieros como los microseguros, los cuales están diseñados para cubrir necesidades específicas, tanto en aspectos de salud, como

\footnotetext{
${ }^{3}$ Este evento tuvo lugar en Washington D.C. en febrero de 1997 y fue organizado por el Results Educational Fund donde se reunieron más de 2.900 personas de 137 países y contó con la presencia tanto de líderes de la industria microfinanciera como Jefes de Estado y representantes de agencias de la ONU.
} 
protección de inmuebles o cuestiones de tipo agrario. Respecto al segundo, a la garantía de devolución del crédito, se ha asumido que tal devolución es efectiva debido a que los créditos son otorgados a los grupos de autoayuda constituidos por personas que asumen de una forma solidaria la garantía. No obstante, aquí hay que tener en cuenta la buena gestión de supervisión por parte de la institución microfinanciera matriz sobre las instituciones que funcionan como sucursales a fin de garantizar la transparencia a la hora de conceder los microcréditos (McCord y Osinde, 2005). En relación al tercero de los mitos, a la vinculación del microcrédito con la pobreza, se cree que éste constituye el remedio para la disminución de la pobreza, y si bien es cierto que el microcrédito es una buena herramienta para ello, es evidente que ésta debe ir de la mano de otras medidas como pueden ser políticas eficientes del Estado que aseguren el acceso a los servicios básicos de salud y educación en pro del mejoramiento de la calidad de vida de la población local. Finalmente, el último mito hace referencia a la creencia de que las instituciones microfinancieras tienen beneficios, lo que es relativo, ya que ello está influido por aspectos como las características de los mercados locales $^{4}$, el enfoque de la entidad o la etapa en la que se encuentre la entidad, ya que generalmente en la etapa inicial estas entidades funcionan mayoritariamente de forma subvencionada. Por lo tanto, si bien todas estas cuestiones han formado parte del desarrollo del microcrédito, a medida que esta herramienta ha ido logrando un posicionamiento dentro de la población pobre se han ido esclareciendo dichos mitos a través de las actividades de capacitaciones y experiencias propias de los beneficiados.

En la actualidad, el microcrédito se ha convertido en un movimiento mundial. En el año 2005 las Naciones Unidas declararon el año internacional del microcrédito y un año más tarde se le concedió el Premio Nobel de la Paz a Muhammad Yunus por la creación de los microcréditos. De hecho, gobiernos, donantes, agencias de desarrollo, bancos, universidades, consultores y filántropos entre otros, demuestran cada vez más un mayor interés en él. De hecho, su continua expansión se debe en gran medida a la motivación de poderlo utilizar como una herramienta para contribuir al alivio de la pobreza, a través de la inclusión financiera de las comunidades marginadas ${ }^{5}$. Por lo tanto, el precepto prevé que los resultados de las microcréditos son para estimular el espíritu empresarial, incrementar los ingresos y contribuir al empoderamiento y desarrollo de los más pobres, especialmente de las mujeres.

\footnotetext{
${ }^{4}$ Por ejemplo el hecho que el mercado sea rural o urbano ya que ello afectará los costos y gastos de la institución

${ }^{5}$ De hecho la extensión alcanzada por el microcrédito, recopilada por la Cumbre Latinoamericana y del Caribe para el Microcrédito celebrado en el 2005 en Santiago de Chile, fue de 54,8 millones de clientes incluyendo a 26,8 millones de personas en estado de pobreza cuando comenzaron con el programa.
} 
De forma general, los clientes típicos de los microcréditos son personas pobres y de bajos ingresos que no tienen acceso a instituciones financieras formales. Los datos sobre la situación de pobreza de estos clientes son limitados, pero tienden a afirmar que la mayoría están cerca de la línea de la pobreza, tanto por encima como por debajo (CGAP, 2005). De hecho el impacto del microcrédito sobre la reducción de la pobreza, ha sido más estudiado que el impacto de otras formas de microfinanzas. Pues un aspecto duro de la pobreza es que los ingresos a menudo son irregulares y variables y a través de un microcrédito se puede brindar ayuda a la gente pobre para sosegar los flujos de efectivo y evitar períodos donde el acceso a alimentos, ropa, vivienda o educación se pierde.

\subsection{Dos enfoques diferenciados}

Más allá del consenso establecido respecto al fin último de las microfinanzas, y de su potencial impacto en el desarrollo local o en el alivio de la pobreza, son las formas de alcanzar dichos resultados los que acarrean los mayores debates en la literatura especializada. Dos enfoques son los protagonistas de este debate, diferenciándose según la elección de la población objetivo, los servicios adicionales que se deben ofrecer, las prioridades del microcrédito -si el acceso a los servicios financieros o la sostenibilidad financiera- y el impacto que se genera en términos de reducción de la pobreza. Según el posicionamiento en dichos aspectos podemos diferenciar dos grandes enfoques sobre el microcrédito: por un lado el de "autosuficiencia financiera" llamado también "minimalista" o "institucionalista" y por otro el conocido como "alivio de la pobreza", "welfarista" o "integral”6 (Brau y Woller, 2004; Woller, Dunford y Woodworth, 1999). El objetivo del trabajo consistirá en ver si tal diferenciación se da en la realidad y hasta qué punto existe el mencionado trade off entre ambos enfoques o puede, por el contrario, asegurarse la consecución de ambos objetivos a la vez. Si bien estudios recientes apuntan que en una primera aproximación hay poca evidencia del trade off entre sostenibilidad y alcance, superándose tal incompatibilidad, estos mismos análisis afirman que tal trade off sí se observa cuando se realiza un análisis más desagregado de los patrones de rentabilidad y tasas de retorno de las instituciones de microcrédito, en

\footnotetext{
${ }^{6}$ En adelante cuando se haga referencia a los modelos, serán mencionados como "autosuficiencia financiera" y "alivio de la pobreza".
} 
concreto cuando se tiene en cuenta la metodología de la entidad para dar acceso al microcrédito $^{7}$ (Cull et al, 2006).

El primero de los enfoques, el de "autosuficiencia financiera", representado por actores institucionales destacados como el Grupo Consultivo de Ayuda a los Pobres (CGAP) y la Agencia de los Estados Unidos de América para el Desarrollo Internacional (USAID), afirma que la población objetivo del microcrédito son los "menos pobres entre los pobres", acentúa la sostenibilidad financiera de la oferta -de la entidad-, y en cuanto a los servicios ofrecidos promueve la especialización financiera. Se considera así que si el microcrédito por sí solo permite mejorar las condiciones socioeconómicas de las personas, es éste servicio específico el que debe alcanzar a la mayor cantidad de potenciales prestatarios posible. Por lo tanto se insiste en la especialización en un solo servicio -el microcrédito- sin ofrecer otro tipo de servicios complementarios, ya que solo así puede alcanzarse la efectividad del desarrollo económico, ofrecer un servicio eficiente y garantizar la sostenibilidad institucional. De ahí que desde este enfoque se afirme que la capacitación, la asistencia y otros servicios no financieros aumentan los costos de las instituciones microfinancieras, recargan las tareas administrativas y encarecen los costos para los prestatarios, sin que ello se traduzca en beneficios tangibles significativos para la institución. Por lo tanto, para este enfoque las prioridades son primero la sostenibilidad y segundo el alcance -nivel de pobreza de los prestatarios-, siendo el impacto un resultado que se da por supuesto como fruto del propio alcance (González Vega, 2002; Von Pischke, 2002).

En lo referente al segundo enfoque denominado como "alivio de la pobreza", generalmente representado por la Cumbre de Microcrédito se sostiene que la población objetivo deben ser principalmente "los más pobres entre los pobres" enfatizando el impacto en términos de pobreza y a su vez en ofrecer adicionalmente al servicio del microcrédito otros servicios no financieros como facilitar espacios de encuentro y el desarrollo de capacitaciones (Yunus, 2002; McNelly, 1998; Dunford, 2000). En este enfoque se reconoce la necesidad de capacitación y asistencia técnica a los prestatarios de las instituciones microfinancieras, si el objetivo es generar actividades sustentables y generadoras de excedente económico. La aplicación de este enfoque significa otorgar a los prestatarios de las instituciones microfinancieras una combinación coordinada de servicios de microfinanzas y otros servicios

\footnotetext{
${ }^{7}$ Las principales son: los préstamos individuales, los grupos solidarios, los fondos rotatorios y los bancos comunales.
} 
de desarrollo para mejorar sus microempresas, ingresos y bienes, salud, nutrición, planificación familiar, la educación de sus niños, redes de apoyo social, entre otros. Así para este enfoque es prioritario el impacto en los más pobres y el alcance, y dejan a otras circunstancias la sostenibilidad financiera.

Ambos enfoques presentan una clara similitud o coincidencia en términos de alcanzar la mayor cantidad de prestatarios posibles por lo que ambos se relacionan directamente con la categoría de la escala (número de clientes), y por lo tanto con el alcance (grado de pobreza de los clientes). Por otro lado, el mayor rasgo diferenciador lo encontramos en la oferta de servicios ya que dependiendo de cuál sea, si apuestan por la especialización de un servicio (“autosuficiencia financiera") o por el contrario tienen un portafolio de servicios amplio (“alivio de la pobreza”), ello quedará reflejado en la incidencia sobre la sostenibilidad financiera, específicamente en los indicadores de costos por prestatario y gastos operativos.

A pesar de esta diferenciación debe subrayarse que la búsqueda de la sostenibilidad financiera es un requisito imprescindible independientemente del enfoque por el que opte la entidad microfinanciera. En relación a ello se han descrito cuatro mecanismos que logran incidir de manera positiva en la sostenibilidad financiera, los cuales intentan conseguir altas tasas de repago y reducir al máximo los altos costos (Morduch, 1999). Estos mecanismos son: i) la "selección adversa" que se basa en realizar los préstamos bajo la metodología grupal y no individual ya que el préstamo grupal presenta mayores beneficios potenciales tanto para el prestamista como para los prestatarios; ii) el "riesgo moral" que se genera en el momento en que el prestatario tiene el crédito y la institución desconoce si realmente el dinero será utilizado para los fines que se declararon en el contrato. De nuevo la metodología grupal ayuda a minimizar este riesgo; iii) el "contrato de incentivos dinámicos" que consiste en iniciar los préstamos con pequeños montos los cuales se van aumentando a medida que el prestatario demuestre un nivel de repago puntual y responsable; y iv) los "planes de pago regulares" que hace referencia a que una vez el prestatario obtiene el préstamo debe iniciar inmediatamente los pagos acordados en los tiempos estipulados en el contrato. De hecho, si bien todos estos mecanismos hacen referencia a los beneficios de los microcréditos para las dos partes involucradas (prestamistas y prestatarios), en la práctica actual muchos de estos beneficios no se cumplen. El más cuestionado hace referencia a la sostenibilidad financiera ya que si bien la teoría indica que las instituciones microfinancieras pueden recuperar los créditos y adicionalmente a ello obtener rendimientos, muchas de estas instituciones no han 
logrado tal sostenibilidad ya que existen restricciones a las que la institución debe enfrentarse como son la poca penetración de mercado, la politización y la corrupción (Morduch, 2000).

Por último mencionar la dificultosa tarea de medir el impacto del microcrédito. El análisis de la relación entre microcrédito y pobreza se ve a menudo complicada por la ausencia de datos confiables, no pudiéndose en la mayoría de los casos saber si realmente las familias con acceso al microcrédito han logrado una mejora en su calidad de vida. Esta dificultad en los datos se debe a que en el momento de realizar las encuestas se torna complejo el saber si los encuestados están dando una información verdadera, si realmente utilizaron el dinero prestado en lo que dice el contrato, si han sido beneficiados de forma económica, o que situación hubieran vivido sino hubieran obtenido el préstamo. No obstante, es cierto que la mayoría de estudios de impacto del microcrédito han encontrado beneficios significativos mostrando indicaciones que confirman que los prestatarios del microcrédito han mejorado su nivel de vida (Woller y Parsons, 2002), si bien algunos mencionan la sobrestimación del efecto "milagroso" del microcrédito para salir de la pobreza. En este sentido se apunta que si bien el acceso al microcrédito permite a hogares pobres invertir en sus pequeños negocios e incluso modificar la estructura del gasto doméstico ello no significa un cambio significativo en el nivel de pobreza de estas familias (Banerjee et al, 2013). Por otro lado, también se ha estudiado con profundidad el desempeño social de la entidad microfinanciera y por lo tanto su impacto en términos de mejora del bienestar de los destinatarios, observándose que este viene en gran parte determinado por las características de la propia instituciones, estimándose que son las más jóvenes, las menos reguladas, las que presentan un mayor volumen de activos y las que presentan mayores ratios de créditos por personal de la entidad las que desempeñarán mejor su función social (Awaworyi y Marr, 2012).

No obstante, muchos de estos estudios empíricos sobre el impacto del microcrédito generalmente suscitan discusiones sobre la metodología utilizada. Algunos autores como Murdoch (2002) en su análisis sobre tales impactos cuestiona algunas metodologías de estudio afirmando que el impacto de los microcréditos no se refleja directamente en la reducción de la pobreza sino más bien en la reducción de las vulnerabilidades de la gente pobre, lo que significa una especie de estabilización circunstancial del consumo y de la oferta de trabajo. Por ello, puede deducirse que la mayoría de estudios tienden a evaluar impactos de corto plazo siendo necesario que haya un avance en las actuales técnicas de evaluación para 
que permitan exponer si los cambios positivos son sostenibles y si realmente posibilitan progresos en la calidad de vida de la población en situación de pobreza ${ }^{8}$.

\subsection{Microcrédito y género}

Uno de los temas ampliamente abordado en la literatura sobre microcrédito ha sido la referente al impacto que el microcrédito puede tener sobre la mejora de la situación de la mujer en el mundo en desarrollo, ya sea desde una perspectiva estrictamente economicista acceso a los recursos por parte de la mujer- o aquella más amplia del empoderamiento que completa la visión tradicional del incremento de los ingresos con los cambios que ello puede conllevar en términos de desarrollo humano y de transformación de las relaciones de género.

Concretamente Mayoux (2000) nos brinda una excelente aproximación sobre los tres paradigmas que conceptualmente se podrían diferenciar en el estudio sobre microcrédito y género, las formas de intervención y la sostenibilidad de los programas. El primero de ellos es el paradigma de la sostenibilidad financiera, vinculado al enfoque de "autosuficiencia financiera", el cual relaciona el empoderamiento de la mujer con aspectos básicamente de tipo económico, de forma que la sostenibilidad es medida sólo sobre la base de la situación financiera de la entidad, que tiende a preferir a las mujeres por ser mejor clientes ${ }^{9}$. El segundo paradigma es el de la reducción de la pobreza, relacionado con el enfoque de "alivio de la pobreza", donde se trabaja con las mujeres entendiendo que la pobreza se concentra en ellas, quienes como responsables de sus hogares, en la medida que acceden a un crédito ello se verá reflejado en un aumento del bienestar y desarrollo local. Por último tenemos el paradigma del empoderamiento de las mujeres que difiere de los dos primeros al poner el énfasis en la búsqueda de la igualdad de géneros, usando al microcrédito como herramienta para el empoderamiento económico, político y social de las mujeres.

En paradigma del empoderamiento ha destacado tres tipos de impactos positivos que se dan en la relación entre microcrédito y género. En primer lugar en el ámbito financiero ya que el microcrédito dirigido a las mujeres muestra una mayor tasa de reembolso confirmándose que las mujeres son mejoras ahorradoras (Dunford y Denman, 2001). En

\footnotetext{
${ }^{8}$ Adicionalmente el hecho que el sector microfinanciero caiga en el asistencialismo condiciona también a su vez tales mediciones de impacto.

${ }^{9}$ Sobre el sesgo de género en el acceso al microcrédito se llega a conclusiones aparentemente contradictorias, al observarse que si bien el acceso al crédito es neutral en términos de género, las mujeres enfrentan mayores dificultades para endeudarse debido a su estatus social y familiar (Agier et al, 2013).
} 
segundo lugar en términos de desarrollo, porque de toda la población pobre en el mundo un gran porcentaje son mujeres, y son ellas quienes destinan mayoritariamente los ingresos a mejorar la calidad de vida de sus hogares, dejando en segundo lugar otros usos de tales ingresos como puede ser el consumo personal (Pitt y Khandker,1998). Y por último, en el empoderamiento debido a que el acceso al microcrédito incrementa el poder de decisión de las mujeres, lo que queda reflejado en el aumento de la participación activa dentro de su $\operatorname{hogar}^{10}$ tomando decisiones y participando en la planificación familiar (Mayoux, 2001). Si bien es cierto que ha habido planteamientos críticos en este supuesto vínculo positivo ${ }^{11}$, los estudios de impacto concluyen mayoritariamente que el acceso de la mujer al microcrédito le permite el desarrollo de actividades económicas que conllevan una ampliación de su campo de acción y de la toma de decisiones tanto en el ámbito personal como familiar, pudiendo en algunos casos significar incluso la independencia económica (Morduch, 2007; Pitt, Khandker y Cartwright, 2006; Ngo, 2011).

En cualquier caso la consideración generalizada de tal relación positiva entre microcrédito y mujer, en términos no solo de desarrollo sino también financieros, ha conducido a las entidades microfinancieras a reevaluar y revisar algunos de sus criterios sobre sus programas crediticios. El hecho que el número de mujeres que han accedido a microcréditos en la última década ha aumentado de 10,3 millones (1999) a 104,7 millones (2009) (Cumbre del Microcrédito, 2011) hace que las interrelaciones y sinergias resultado del acceso de la mujer al microcrédito sean fundamentales. Ello se evidencia en el informe del BID (2003) cuando se hace una clara apuesta por orientar los microcréditos a las mujeres para así obtener un mayor impacto en términos de alivio de la pobreza. También en los programas del Banco Mundial (2012) los temas de empoderamiento de las mujeres son explícitos, como se evidencia al afirmarse que es posible lograr un aumento significativo en el empoderamiento de la mujer a través de la mejora en la productividad, ya que las mujeres constituyen más del $40 \%$ de la mano de obra mundial, el $43 \%$ de la mano de obra agrícola y son más de la mitad de los estudiantes universitarios de todo el mundo.

\footnotetext{
${ }^{10}$ Por ejemplo Berezo (2005) destaca la redistribución de la propiedad hacia las mujeres mediante la inclusión de sus nombres en los documentos de propiedad siendo este un mecanismo efectivo para incrementar su acceso al crédito al convertirse aquel en un aval financiero.

${ }^{11} \mathrm{Al}$ considerar por ejemplo que al ser muy limitados los recursos de que disponen las mujeres (se trata de montos muy pequeños) ello dificulta el desarrollo de un negocio y por tanto de la mejora socioeconómica.
} 
Recapitulando, hemos planteado aquí la existencia de dos enfoques teóricos sobre microcrédito, vinculados respectivamente a la "autosuficiencia financiera" y al "alivio de la pobreza", con especial mención a la vinculación del microcrédito con aspectos de género, concretamente en como el acceso de la mujer a los mismo puede tener impactos positivos en términos tanto financieros como de desarrollo. El siguiente paso es contrastar empíricamente la hipótesis anunciada, a saber, si se confirma la existencia de una diferenciación de dos modelos de microcréditos a nivel mundial a partir de identificar como el microcrédito se caracteriza en las cuatro grandes regiones del mundo en desarrollo. Y a su vez validar si la participación de la mujer en el acceso al microcrédito domina en alguno de ellos, y si ello tiene incidencia en el aspecto del alcance.

\section{MODELOS REGIONALES DE MICROCRÉDITO}

\subsection{Metodología}

El análisis global que aquí se plantea parte de la realización de una comparativa mundial por regiones en base a la utilización de indicadores económicos universales que nos han permitido medir de forma homogénea aspectos financieros y sociales. Cabe recordar, como se ha mencionado anteriormente, que este es un sector muy heterogéneo con distintas metodologías de servicio y enfoques, por lo que aquí se agruparan instituciones microfinancieras (IMFs) que son distintas entre sí. No obstante, en la medida que trabajamos con datos financieros comparables y homogéneos ello nos permite estudiar los rasgos de los diferentes modelos de microcrédito que se dan en el mundo y comprobar si efectivamente existen de forma diferenciada ambos modelos, y a la vez verificar si existe un trade off entre el modelo financiero y el social.

La verificación de tal hipótesis se ha realizado con una metodología de tipo comparativo utilizando diez indicadores recopilados de 763 IMFs, distribuidas en cuatro regiones: África, América Latina y El Caribe, Asia Meridional y Oriente Medio/África del Norte. La principal fuente de información utilizada ha sido la base de datos del MixMarket ${ }^{12}$. El universo de la investigación está conformado por los 94 países que reportan en esta base de datos y la elección de la muestra se ha realizado mediante la aplicación del modelo de

\footnotetext{
${ }^{12}$ Esta plataforma se desarrolla a través del Microfinance Information Exchange Inc. siendo ésta una de las organizaciones más importantes a nivel mundial en presentación de datos y análisis sobre el desempeño del sector microfinanciero.
} 
selección de muestra representativa descrito por Pita (1996) ${ }^{13}$. El resultado obtenido ha sido una muestra de 47 países distribuidos en las cinco regiones, de donde se recopilan los datos de un total de 763 IMFs. La elección de los países se ha realizado de acuerdo a aquellos que tienen mayor cantidad de instituciones microfinancieras.

La elección de los diez indicadores responde a su relación con las dos dimensiones que nos permitirán caracterizar el modelo de microcrédito. Estas dos categorías que nos remiten a los dos modelos mencionados -financiero y social- son la sostenibilidad financiera (enfoque "autosostenibilidad financiera") y el alcance (enfoque "alivio de la pobreza). La sostenibilidad además de referirse a la viabilidad futura del proyecto asociándolo a criterios de productividad y eficiencia, también se vincula a la búsqueda de beneficios. Por otro lado el alcance nos informa del grado de pobreza de los clientes atendidos, además del tamaño de la clientela ${ }^{14}$ de la institución microfinanciera.

Tabla 1. Indicadores del sector microfinanciero

\begin{tabular}{|c|c|}
\hline Categorías & Indicadores \\
\hline \multirow[t]{5}{*}{$\begin{array}{l}\text { Sostenibilidad } \\
\text { Financiera }\end{array}$} & $\begin{array}{l}\text { - Costo por prestatario } \\
\text { Es una medida significativa de la eficiencia al mostrar el costo } \\
\text { promedio de mantener un prestatario activo. A menor índice, mayor } \\
\text { es la eficiencia. }\end{array}$ \\
\hline & $\begin{array}{l}\text { - Gastos operativos/activos } \\
\text { Este indice da a conocer el costo operativo para administrar de } \\
\text { forma eficiente sus activos. }\end{array}$ \\
\hline & $\begin{array}{l}\text { - Gastos financieros/activos } \\
\text { Esta medida ofrece indicios sobre los gastos financieros que la IMF } \\
\text { tiene al financiarse con recursos ajenos para poder prestar sus } \\
\text { servicios financieros. }\end{array}$ \\
\hline & $\begin{array}{l}\text { - Ingresos financieros/activos } \\
\text { Este indice refleja tanto el margen de ingresos como la eficiencia de } \\
\text { la institución. }\end{array}$ \\
\hline & $\begin{array}{l}\text { - Prestatarios por miembro del personal } \\
\text { Muestra la productividad del personal de la institución, cuanto más } \\
\text { alto es el índice más productiva es la institución. }\end{array}$ \\
\hline Alcance & - Monto promedio de crédito por prestatario \\
\hline
\end{tabular}

13 Fórmula del modelo de selección de la muestra $(n)$, donde $N=$ Total de la población, $Z=$ probabilidad, $Z_{\alpha}{ }^{2}$ $=1,645^{2}$ (con una seguridad del 90\%), $p=$ proporción esperada; $q=1-\mathrm{p}, d=$ precisión.

$\mathbf{n}=\frac{N * Z \alpha^{2} * p * q}{d^{2} *(N-\mathbf{1})+Z \alpha^{2} * p * q}$

${ }^{14}$ También conocido como "escala". 


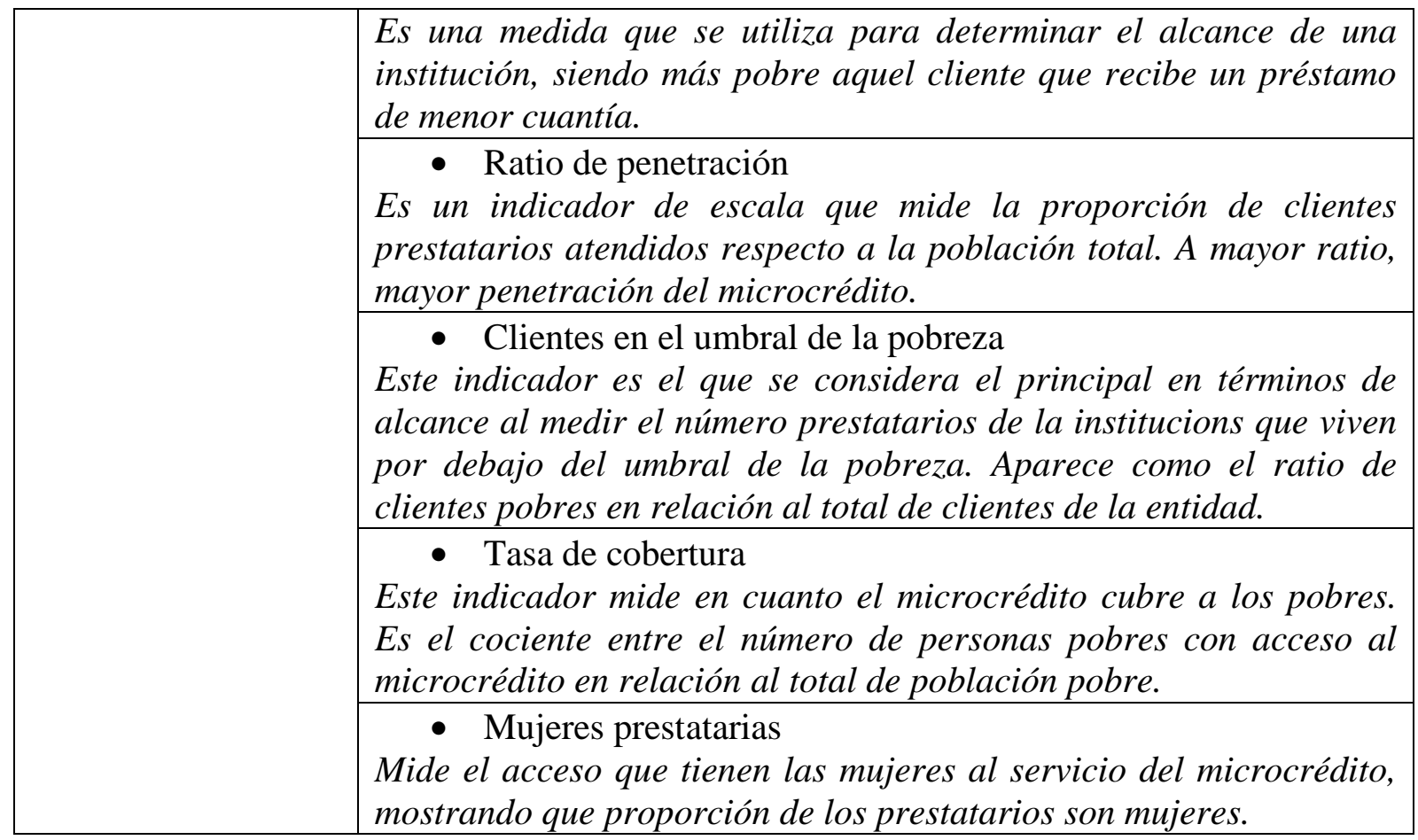

El análisis de los datos que sigue a continuación se ha realizado teniendo en cuenta una serie de patrones que se deben poner de manifiesto en cada una de las variables para determinar si existe o no una sostenibilidad financiera ${ }^{15}$ y la amplitud de las proporciones de la escala y el alcance. Referente a la sostenibilidad financiera los indicadores deben manifestar tres aspectos: una baja dependencia de recursos financieros, un nivel bajo de costos y gastos y por último mostrar eficiencia por parte del personal de la institución microfinanciera. En cuanto al alcance se debe evidenciar que la mayoría de los clientes se encuentran en el umbral de la pobreza, que los clientes son mayoritariamente mujeres, que la tasa de cobertura es elevada, que atienden a un elevado número de clientes y por último observar las cuantías de los préstamos ${ }^{16}$.

\subsection{Análisis de resultados}

Los resultados han sido analizados desde dos perspectivas: en primer lugar, se ha realizado un análisis individual de los indicadores de las dos categorías (sostenibilidad financiera y alcance) y posteriormente se ha estudiado el modelo que predomina en cada

\footnotetext{
${ }^{15}$ La información que ofrece el Mix Market no recoge específicamente el indicador definido directamente como "rentabilidad", de ahí que se trabaje con tres indicadores que informan de la viabilidad financiera (gastos operativos/activos, gastos financieros/activos e ingresos financieros/activos).

${ }^{16}$ Entendiendo que cuanto menores son los créditos más pobres son los clientes.
} 
región, donde se desvelan los modelos financiero y social con el que los prestatarios acceden al microcrédito.

\section{Análisis de indicadores}

En la tabla 2 y 3 se presentan los resultados de los diez índices por cada una de las regiones agrupados por categoría de estudio, sostenibilidad financiera y alcance, para posteriormente desarrollar el análisis comparativo de cada indicador.

Tabla 2. Sostenibilidad Financiera de las IMFs por regiones (2010)

\begin{tabular}{|l|c|c|c|c|}
\hline & $\begin{array}{c}\text { América Latina } \\
\text { y el Caribe }\end{array}$ & $\begin{array}{c}\text { Asia } \\
\text { Meridional }\end{array}$ & África & $\begin{array}{c}\text { Oriente Medio y } \\
\text { África del Norte }\end{array}$ \\
\hline $\begin{array}{l}\text { Costo por } \\
\text { prestatario (US\$) }\end{array}$ & 338 & 87 & 206 & 131 \\
\hline $\begin{array}{l}\text { Gastos } \\
\text { operativos/activos }\end{array}$ & $20 \%$ & $13 \%$ & $24 \%$ & $17 \%$ \\
\hline $\begin{array}{l}\text { Gastos } \\
\text { financieros/activos }\end{array}$ & $5,1 \%$ & $6,5 \%$ & $3 \%$ & $3,9 \%$ \\
\hline $\begin{array}{l}\text { Ingresos } \\
\text { financieros/activos }\end{array}$ & $42 \%$ & $21 \%$ & $35 \%$ & $25 \%$ \\
\hline $\begin{array}{l}\text { Prestatarios por } \\
\text { miembro de } \\
\text { personal }\end{array}$ & 119 & 151 & 132 & 128 \\
\hline
\end{tabular}

Fuente: Elaboración propia a partir de datos del MixMarket (2011), del Banco Mundial (2011) y de la Campaña de la Cumbre de Microcrédito (Reed, 2011).

Tabla 3. Alcance de las IMFs por regiones (2010)

\begin{tabular}{|l|c|c|c|c|}
\hline & $\begin{array}{c}\text { América } \\
\text { Latina y el } \\
\text { Caribe }\end{array}$ & $\begin{array}{c}\text { Asia } \\
\text { Meridional }\end{array}$ & África & $\begin{array}{c}\text { Oriente Medio } \\
\text { y África del } \\
\text { Norte }\end{array}$ \\
\hline $\begin{array}{l}\text { Monto promedio por } \\
\text { prestatario (US\$) }\end{array}$ & 3.822 & 185 & 595 & 717 \\
\hline Ratio de penetración & $2,83 \%$ & $2,09 \%$ & $0,44 \%$ & $0,15 \%$ \\
\hline $\begin{array}{l}\text { Clientes en el } \\
\text { umbral de la pobreza }\end{array}$ & $62 \%$ & $56 \%$ & $70 \%$ & $25 \%$ \\
\hline Tasa de cobertura & 17 & $64,2 \%$ & & $9,8 \%$ \\
\hline $\begin{array}{l}\text { Mujeres } \\
\text { prestatarias/total } \\
\text { prestatarios }\end{array}$ & $46 \%$ & $91 \%$ & $64 \%$ & $62 \%$ \\
\hline
\end{tabular}

Fuente: Elaboración propia a partir de datos del MixMarket (2011), del Banco Mundial (2011) y de la Campaña de la Cumbre de Microcrédito (Reed, 2011).

\footnotetext{
${ }^{17}$ El dato ofrecido por el informe de la Campaña de Crédito para la región de Asia lo hace en su totalidad (Asia meridional y oriental) y para las regiones de África y Oriente Medio/África del Norte ofrece el dato en forma conjunta.
} 
En el caso de los indicadores que nos informan sobre el grado de sostenibilidad financiera de la entidad, tenemos en primer lugar el índice de costo por prestatario. Los resultados muestran que Asia Meridional tiene el índice más bajo, lo que significa que en esta región las IMFs manejan procesos muy eficientes (simples y de bajo costo) en la operación de la institución lo que incrementa así su grado de eficiencia. En un caso totalmente contrario se encuentran América Latina y África con los índices más altos. Del total de los 37 países de la muestra, el país con el menor costo es India con USD 14 y el país con el mayor costo es Costa Rica con USD 894. De hecho cuando las instituciones microfinancieras se especializan en préstamos de cuantías pequeñas éstas deberán mantener sus costos por prestatarios muy por debajo de los USD 100 (CGAP, 2007) a fin de contrarrestar que sus gastos operativos sean altos. Teniendo en cuenta este concepto se puede afirmar que de forma general el costo del prestatario deberá ser proporcional al tamaño del préstamo, con lo que se puede entrever que América Latina es la zona con los préstamos de mayor cuantía.

Los gastos operativos, que hacen referencia a todos los gastos relacionados con la operación de la institución -gastos administrativos, salarios, depreciaciones y honorarios de directores- pueden llegar ser de USD 15, USD 20 o inclusive USD 30 por cada 100 dólares en la cartera de créditos (CGAP, 2007). Por lo tanto el indicador de eficiencia, en este caso, gastos operativos sobre activos, deberá estar entre el 15\%, 20\% o 30\%. Los resultados enseñan que todas las regiones tienen el índice dentro de este parámetro. No obstante, África es la región que tiene el mayor índice (24\%), que comparado con el de Asia Meridional (13\%) marca una diferencia muy significativa, lo que muestra que Asia Meridional lleva a cabo sus operaciones casi con la mitad de gasto que lo realiza África.

Los gastos financieros que hacen alusión a intereses, comisiones, tasas de cambio, junto con otros gastos de las operaciones financieras, revelan más que nada si la IMF se financia básicamente a través de deuda, de capital propio o subvenciones. Los resultados manifiestan que Asia Meridional y América Latina tienen los gastos financieros con mayor incidencia sobre el total de sus activos con valores de 6,5\% y 5,1\% respectivamente. En la medida que estas zonas tienen un mayor nivel de endeudamiento que las demás, pagando más en intereses y primas por todo tipo de deudas contraídas, se evidencia también que tienen un mejor apalancamiento financiero ${ }^{18}$ que África y Oriente Medio/África del Norte. La región

\footnotetext{
${ }^{18}$ Se entiende por apalancamiento financiero la utilización de la deuda para incrementar la rentabilidad del capital propio.
} 
africana en este caso es la que muestra el índice más bajo (3\%) lo que da una idea de cuán subvencionada se encuentran las IMFs, ya que su capital proviene mayoritariamente de donaciones, y al no poseer un capital propio que sirva de respaldo para obtener una deuda ante otras entidades financieras, les disminuye el margen de rentabilidad.

El índice de ingresos financieros sobre activos revela lo que la IMF realmente recibe de sus clientes por el pago de intereses. Los resultados muestran que las IMFs de América Latina y África obtienen más ingresos en relación al total de activos que todas las demás regiones (42\% y 35\% respectivamente). Asia Meridional (21\%) y Oriente Medio/África del Norte $(25 \%)$ muestran que con menos intereses cobrados logran cubrir el total de sus gastos operativos y financieros como hemos visto en los indicadores previos. Por lo tanto en la medida que este indicador nos muestra la carga financiera sobre los clientes, nos plantea la reflexión sobre si la IMF debe buscar la posibilidad de financiarse a sí misma a través de intereses cobrados - como es el caso de América Latina- o hacerlo aumentando su eficiencia y productividad para obtener un mayor número de clientes -como lo demuestra Asia Meridional-. En el caso de África puede explicarse su margen amplio de ingresos debido a que se encuentra en plena etapa de desarrollo, y está buscando cierto grado de independencia que le permita dejar poco a poco su dependencia de subvenciones y/o donaciones. Si logran una acumulación suficiente de capital, podrían en un futuro lograr un mayor apalancamiento financiero. Situación que no comparte América Latina pues allí el microcrédito es una herramienta desarrollada hace mucho tiempo y las IMFs se han decantado por obtener la autosostenibilidad a través de ingresos financieros y la utilización de deuda, como se observó en el índice anterior.

El último indicador de sostenibilidad, el índice de prestatarios por miembro de personal, mide la productividad de la entidad, pudiéndose observar que es en Asia Meridional donde mayor es la productividad de sus empleados, sirviendo al mayor número de clientes (151 prestatarios). En el caso e América Latina, con un promedio de 119 prestatarios, es la región que menor productividad muestra en la captación de clientes en créditos, lo que es coherente con el (elevado) índice anterior de ingresos financieros, al contrarrestar su falta de productividad con el cobro de intereses altos. En el caso de África con un promedio de 132 prestatarios se demuestra que, a pesar de cobrar altos intereses, es una región que quiere lograr la autosostenibilidad basándose no sólo en los intereses cobrados sino alcanzando un mayor número de clientes, apuntando así hacia la productividad. La zona de Oriente Medio/África del Norte muestra un buen comportamiento en términos de productividad, en la 
misma dirección de Asia Meridional, pero en una menor dimensión. Estas regiones con altos índice de productividad muestran como las IMFs han adaptado sus procesos y procedimientos al propósito de su actividad empresarial de prestar dinero.

En lo referente a la segunda categoría aquí analizada, la del alcance -que aborda el nivel de pobreza de los clientes- tenemos en primer lugar el dato del monto promedio por prestatario que muestra que la mayor cuantía de dinero prestada por cliente de las cuatro zonas está en América Latina (USD 3.822), que comparada esta cifra con las de Oriente Medio/África del Norte (USD 717) y África (USD 595) es cinco y seis veces mayor respectivamente. La región de Asia Meridional presenta un valor realmente pequeño (USD 185) reflejando que sus clientes son los más pobres entre los pobres de las cuatro zonas. Este índice es muy interesante porque permite comparar el grado de pobreza de los clientes atendidos, ya que medir en función de los ingresos o de la riqueza es difícil, así que este índice que mide el tamaño promedio del préstamo es bastante útil para medir el alcance, siendo más pobre el cliente que recibe un préstamo de menor monto. Por ello es interesante comparar estos valores con el tamaño del crédito medio que se presenta en Europa Occidental donde el monto en esta región alcanza los USD 15.375 (12.000 euros) (European Microfinance Network, 2010). Por consiguiente, en este caso es evidente que el microcrédito no se vincula desde la perspectiva de alivio de la pobreza sino para respaldar la formación de empresas y creación de puestos de trabajo ${ }^{19}$.

En cuanto al índice de ratio de penetración que mide la proporción de clientes prestatarios atendidos respecto a la población total hay dos regiones que muestran los mayores ratios, América Latina con un 2,83\% y Asia Meridional con un 2,09\%, si bien son ratios considerablemente bajos. En cuanto a África $(0,44 \%)$ y Oriente Medio/África del Norte $(0,15 \%)$, su todavía menor relevancia puede explicarse por el hecho de que precisamente estas son las zonas en donde el servicio del microcrédito está todavía en desarrollo y por lo tanto el acceso aún está en proceso de afianzamiento. En cualquier caso estos resultados son mejorables pues el ratio aún sigue siendo muy bajo, aunque las cifras de personas que se benefician del microcrédito año tras año van creciendo en forma exponencial (Cumbre del Microcrédito, 2011).

\footnotetext{
${ }^{19}$ De hecho la crisis actual conllevará cambios en la implementación y desarrollo del microcrédito en los países desarrollados, como en el caso de España, que el microcrédito ya se utiliza como una de las medidas que puede contribuir a la generación de empleo y está siendo dirigido a sectores poblacionales definidos como "jóvenes emprendedores" y "nuevos residentes".
} 
Por lo que se refiere a los clientes en el umbral de la pobreza aquí se muestra la relación entre el número total de clientes atendidos y el número de clientes atendidos que viven en el umbral de la pobreza. En el año 2010 la media de atención a nivel global fue del 49\% (MixMarket, 2010). Los resultados obtenidos en este indicador muestran que a excepción de Oriente Medio/África del Norte con un 25\%, en las otras tres regiones este ratio obtiene un valor promedio del $62 \%$. Sin embargo, este índice debe analizarse con cautela, ya que además de que estos resultados provienen de zonas con situaciones económicas diferentes, este índice muestra un valor relativo. Si se le relaciona con un valor absoluto, como lo es el número total de prestatarios pobres que atiende cada región, se podría comprobar que Asia Meridional se puede ubicar en un primer lugar si bien el indicador (en términos relativos) es del $56 \%$ situándose en tercer lugar por detrás de América Latina que tiene un $62 \%$ y África con un $70 \%$. Sabiendo que Asia Meridional concentra el $22 \%$ de la población mundial es coherente que esta región sea la que mayor número de clientes en el umbral de la pobreza atienda, ya que este valor del 56\% corresponde a más de 19 millones de personas pobres, mientras que en América Latina con el 62\% corresponde a poco más de 10 millones de personas y en África con el $70 \%$ a casi 3 millones de personas.

En relación a la tasa de cobertura, que es la relación entre las familias más pobres que recibieron un crédito y el total de familias que viven en la pobreza absoluta se puede observar que Asia Meridional es la única zona en que la tasa de cobertura guarda concordancia con el índice anterior (clientes en el umbral de la pobreza) con valores del 64\% y un 56\% respectivamente. La región de Asia Meridional es de hecho el único caso en el que ambos indicadores no muestran unas diferencias muy marcadas entre ellos, como sí lo es en las tres regiones restantes. En el caso de América Latina hay una diferencia de casi la mitad -con un $62 \%$ de clientes en el umbral de la pobreza y un 31,2\% de tasa de cobertura-, lo que además es coherente con el valor del monto promedio de crédito que tiene esta región (USD 3.822). Ello se debe a que el acceso en América Latina está dirigido principalmente a pequeños y medianos empresarios, por lo tanto la gran mayoría de personas que se benefician no se encuentran en una situación de pobreza tan marcada, lo que inevitablemente limita la tasa de cobertura de la región. En cuanto a África y Oriente Medio/África del Norte, siendo zonas donde se concentra la mayor tasa de pobreza extrema en el mundo, desafortunadamente tiene la tasa más baja con un $9,8 \%$.

Por último, los datos sobre el acceso de mujeres al microcrédito a través del indicador de mujeres prestatarias sobre el total de prestatarios muestran que las mujeres son la gran 
mayoría de la clientela de las microfinanzas, lo que es un resultado alentador no solamente porque las mujeres están dentro del grupo de los más pobres entre los pobres sino porque son ellas las que tienen un mayor impacto en términos de desarrollo. Concretamente, en el año 2011 fueron 52 millones de mujeres en todo el mundo las que accedieron al microcrédito. En el caso de Asia Meridional con claro predominio de las mujeres en el acceso al microcrédito, con un índice del $91 \%$, es notoria la incidencia que tiene en esta región la metodología utilizada por las IMF como son los grupos de autoayuda (Self Help Groups) los cuales son conformados exclusivamente por mujeres. Esta metodología se relaciona con una costumbre muy arraigada en Asia ya que allí las mujeres se organizan para todo tipo de tareas de tipo social, cultural, y como se evidencia en este índice también en lo financiero, a lo que las microfinanzas se han adaptado. Como muestran los valores de este indicador el protagonismo de las mujeres es una característica común en casi todas las zonas, si bien sorprende que no sea tan notoria como lo es en Asia Meridional. En el caso de América Latina cuyo índice de atención a mujeres no llega al 50\% muestra que allí el enfoque de género no es relevante. De hecho en este caso podría existir un trade-off entre mujeres que reciben préstamos para luchar contra la pobreza y hombres que reciben préstamos para el desarrollo económico de sus actividades comerciales. Igualmente aquí la metodología de préstamos individuales, también es una de las principales causas que influye en esta realidad, donde cada persona se presenta de una forma autónoma para solicitar un crédito, a lo que una mujer en estado de pobreza no tiene forma de presentar ningún tipo de garantía, a diferencia de Asia Meridional, donde los grupos de mujeres tienen la ventaja que representan una garantía solidaria, lo que a las entidades les resulta más confiable.

\section{Análisis por regiones}

El análisis de los resultados obtenidos en los diferentes indicadores de sostenibilidad financiera y de alcance a la población más pobre, ponen de manifiesto que en las cuatro regiones es posible distinguir que modelo de microcrédito se ha desarrollado, ya sea aquel basado en un enfoque de "autosostenibilidad financiera", que podríamos definir como modelo financiero o aquel otro enfoque más orientado al "alivio de la pobreza" que denominamos como modelo social. Podemos observar tales diferencias regionales comparando gráficamente algunos indicadores analizados en la sección anterior, en la dimensión de autosostenibilidad financiera -costo por prestatario (Gráfico 1) e ingresos financieros sobre activos (Gráfico 2)- y en la de alcance -monto promedio por prestatario (Gráfico 3) y mujeres prestatarias (Gráfico 4)-.

REVESCO No 118 - Segundo Cuatrimestre 2015 - ISSN: 1885-8031 - www.ucm.es/info/revesco 
Gráfico 1. Costo por prestatario (USD)

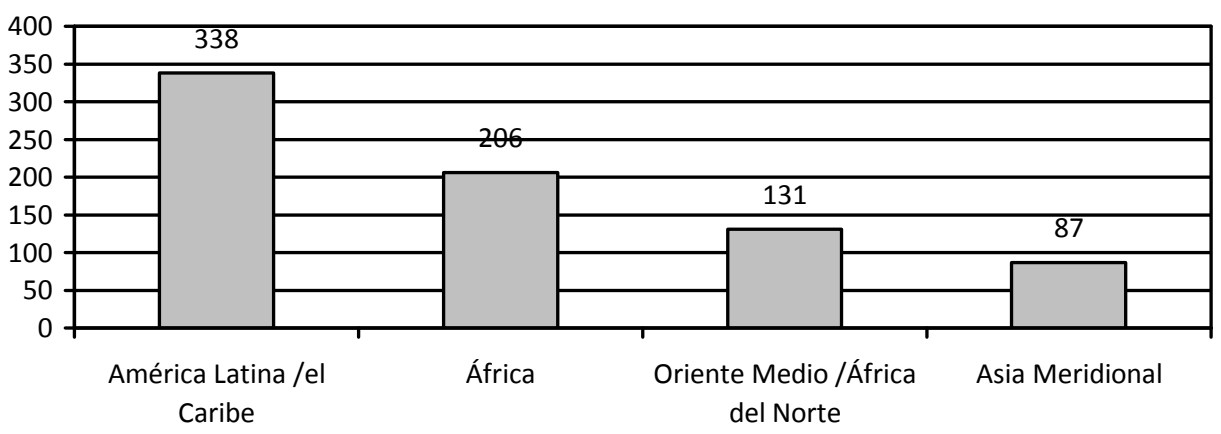

Fuente: Elaboración propia a partir de datos del Mix Market 2011.

Gráfico 2. Ingresos financieros/activos $(\%)$

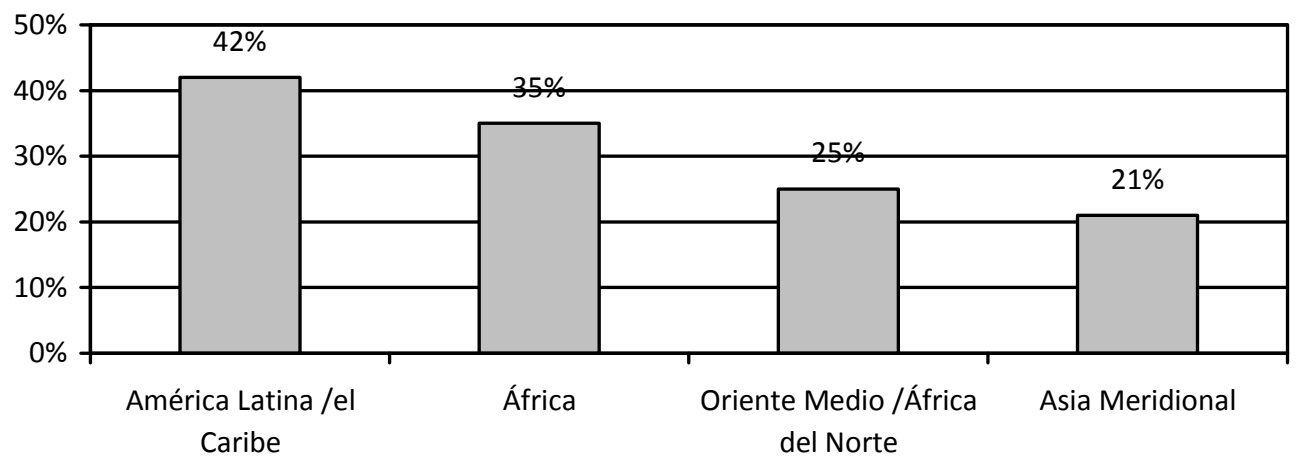

Fuente: Elaboración propia a partir de datos del Mix Market 2011.

Gráfico 3. Monto promedio por prestatario (USD)

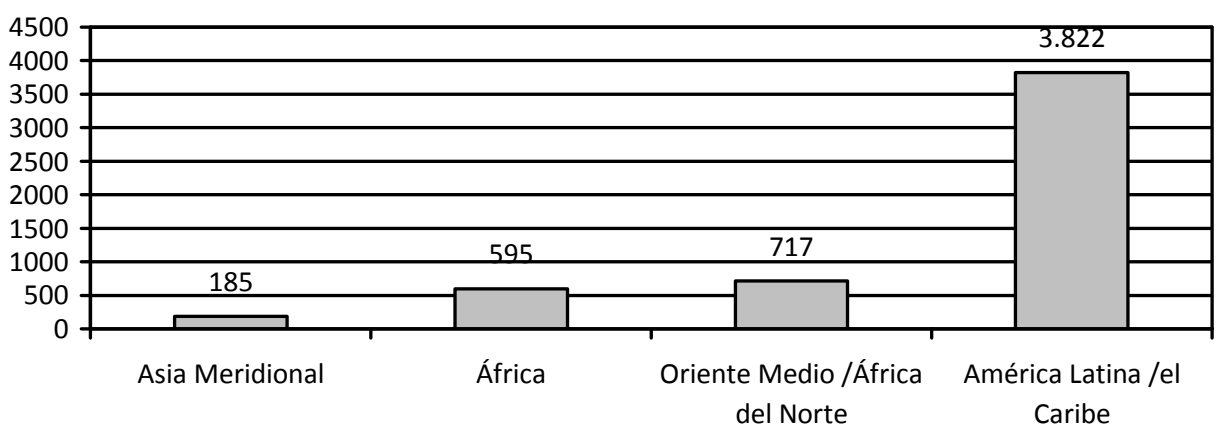

Fuente: Elaboración propia a partir de datos del Mix Market 2011. 
Gráfico 4. Mujeres prestatarias (\%)

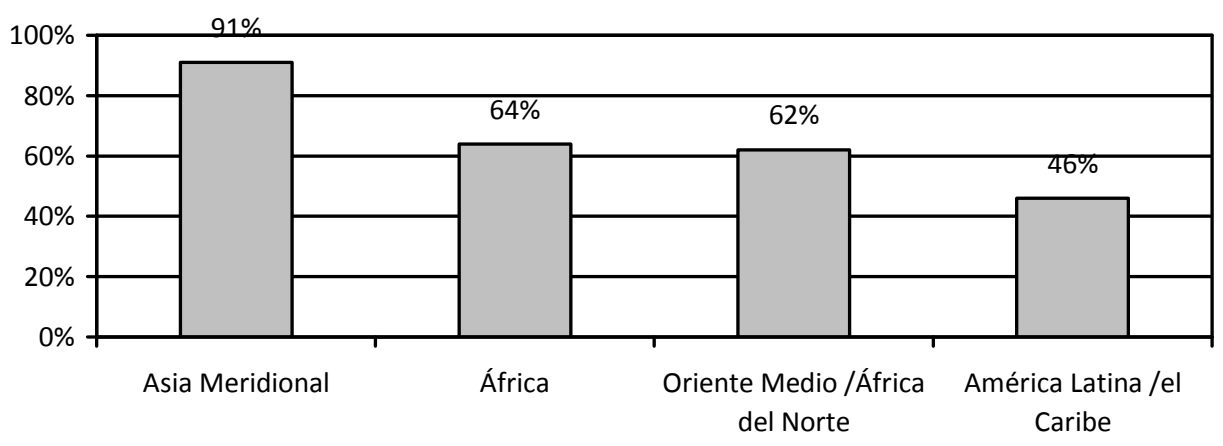

Fuente: Elaboración propia a partir de datos del Mix Market 2011.

Para poder contrastar más netamente la existencia de diferentes modelos regionales de microcrédito se ha procedido a elaborar un índice sintético multivariable ${ }^{20}$ para cada una de las dos categorías, sostenibilidad y alcance, a partir de los indicadores anteriormente analizados. En el Gráfico 5 se recogen gráficamente estos dos índices sintéticos con el fin de observar el predominio de un modelo más financiero o social según la región a la que nos refiramos. Efectivamente puede observarse este diferente posicionamiento según la zona o región, mostrándose como las dos mejores posiciones en sostenibilidad financiera la tienen Asia Meridional y América Latina, mientras que en lo que se refiere al alcance a la población más pobre nuevamente la mejor situada es Asia Meridional seguida de África. Si bien, ya tendríamos una clara diferenciación de unas regiones que han desarrollado un modelo más financiero -América Latina y Caribe- y otras donde predomina un modelo más social de microcrédito -Asia Meridional y África-, se hace necesario proceder a una análisis más detallado del modelo específico de cada región.

\footnotetext{
${ }^{20} \mathrm{El}$ índice sintético se ha calculado mediante una media ponderada donde se incluyen los indicadores de cada categoría, si bien se excluyeron los indicadores de "costo por prestatario" y "prestatarios por miembro de personal" (sostenibilidad financiera) y "monto promedio por prestatario (alcance).
} 
Gráfico 5. Posicionamiento de las regiones según sostenibilidad financiera y alcance (2010).

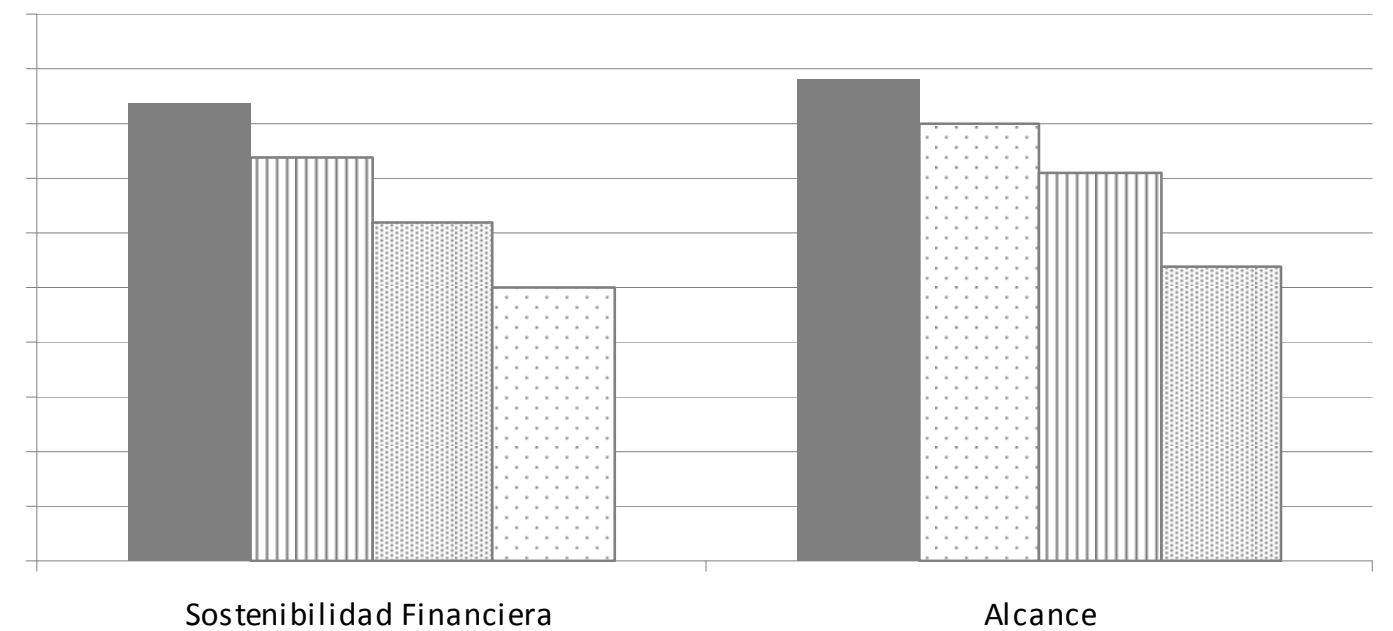

- Asia Meridional $\square$ América Latina/el Caribe $\quad$ Oriente Medio/África del Norte $\square$ África

Fuente: Elaboración propia a partir de datos del MixMarket $(2011)^{21}$.

En el caso de América Latina se observa que las IMFs descansan más bien en un enfoque de "autosostenibilidad financiera", optando así por un modelo más financiero que social, donde el microcrédito es ofrecido apuntando al logro de la sostenibilidad y rentabilidad financiera. El servicio se brinda principalmente a medianas y pequeñas empresas, por lo que la atención a la población en situación de pobreza es limitada. El monto promedio de crédito es muy significativo (USD 3.822) lo que indica que los clientes comparten unas características económicas y empresariales (pequeños y medianos empresarios) que si bien no pertenecen al sector de gente muy pobre, el desarrollo de sus actividades puede contribuir al crecimiento económico. Coherentemente con este enfoque de tipo más financiero, el microcrédito en América Latina se muestra con una alta viabilidad financiera, gracias a los intereses cobrados y a su gran apalancamiento financiero lo que refleja que son IMFs independientes de subvenciones y donaciones. Así, al recurrir a la financiación por parte del sector privado, cada IMF compite por obtener dicha financiación, y la mejor forma para conseguirla es acumular años de experiencia en el sector, mostrando bajos niveles de riesgo, un manejo efectivo de costes y gastos y mostrándose más rentables que su competencia. En este punto es justamente dónde el alcance se ve sacrificado porque en el enfoque de sus

\footnotetext{
${ }^{21}$ Los indicadores sintéticos se obtuvieron a través de una suma ponderada en donde se incluyeron los cinco indicadores que componen cada categoría (sostenibilidad financiera y alcance).
} 
acciones tales como la preferencia de clientes urbanos en vez de rurales o la exigencia de avales, las personas que se ven beneficiadas son aquellas que alcanzan un nivel de renta medio, siendo marginadas aquellas con un mayor grado de pobreza.

En la región de Asia Meridional, al ser la más poblada del mundo y la que más clientes tiene, las IMFs atienden a los más pobres y en su gran mayoría mujeres. En esta región el servicio del microcrédito evidencia tener un enfoque de "alivio de la pobreza". Igualmente se podría pensar que entregar el servicio del microcrédito con una perspectiva social, extrema los riesgos, los costos, poniendo en riesgo la sostenibilidad financiera de la IMF por lo que sería más seguro enfocarse en un mayor grado en la perspectiva financiera. Sin embargo, los índices de Asia Meridional demuestran que ello no tiene que ser necesariamente así, ya que estas IMFs tienen un alcance sostenible debido al gran número de clientes, lo que evidencia que está siendo una buena vía para contribuir a la disminución de la pobreza, a través de la combinación de un servicio focalizado en la población vulnerable, con unas medidas orientadas a crear un sistema financiero competitivo y sostenible. Se confirma pues que el enfoque social sobre el que Asia Meridional ofrece el servicio de microcrédito es también un modelo financieramente viable. Justamente gracias a que es una región altamente productiva y maneja una gran escala de clientes, ello le permite brindar un acceso a un bajo coste.

En el caso de África, estaríamos a caballo entre los dos enfoques, encontrando ahí un modelo que sería una combinación entre la perspectiva financiera y social. Esta región ocupa la segunda posición en cuanto a mayores rendimientos financieros lo que se traduce en términos de autosostenibilidad financiera. Por otro lado, muestra un alcance en la población en situación de pobreza más destacado que Oriente Medio/África del Norte y en comparación con América Latina se observa que la mayoría de sus clientes se encuentran en estado de pobreza. Este comportamiento de África es debido precisamente al proceso de desarrollo que viven las microfinanzas en esta región, pues al ser un sector "joven" las IMFs se encuentran mayoritariamente subvencionadas y por no tener aún un buen apalancamiento financiero cobran intereses altos con el doble propósito de cubrir gastos e ir aumentando poco a poco un capital propio que les permita disminuir su dependencia de las subvenciones. Por tanto, en esa búsqueda de la autosostenibilidad tendrá que forzosamente aumentar la cantidad de sus operaciones microfinancieras lo que previsiblemente le incrementará su número de clientes y ello le podrá facilitar progresar en la dimensión del alcance a la población más pobre. 
Por último, la región de Oriente Medio/África del Norte presenta un enfoque de "autosostenibilidad financiera" al mostrar unos indicadores de sostenibilidad que además de reflejar una recuperación de los fondos invertidos obtiene cierta rentabilidad a un bajo riesgo. Ello sugiere que en esta zona las IMFs no tienen una alta dependencia de los subsidios de los donantes como sucede en África y por el contrario han encontrado un lugar en el mercado que no es de interés por parte de la banca comercial tradicional y que está siendo rentable. En lo referido al alcance, aquellas personas que se encuentran bajo la línea de la pobreza, no conforman su nicho objetivo de mercado, pues sólo el $25 \%$ de sus clientes son pobres. Estaríamos claramente en un modelo más financiero que social.

\section{CONCLUSIONES}

Podemos afirmar en primer lugar que en cualquiera de los dos enfoques teóricos sobre el microcrédito, el de "alivio de la pobreza" o el de "autosostenibilidad financiera", éste se ha convertido en una herramienta financiera que además de ser accedido por personas en situación de pobreza lo puede ser también por personas calificadas como pequeños y medianos empresarios. Sin embargo, este instrumento se utiliza generalmente para mitigar la pobreza y se encuentra siempre en constante evolución para lograr la ampliación de su alcance, el mejoramiento de las técnicas de medición de impacto y la intensificación del enfoque de género.

Los resultados obtenidos permiten concluir que pueden diferenciarse claramente dos modelos de oferta del microcrédito, uno financiero y otro social, y ambos modelos comparten la finalidad de incrementar el acceso a los servicios financieros de personas que se encuentran excluidas del sistema financiero tradicional. La diferencia la encontramos en el público al que va dirigido. Mientras en el modelo social se asiste a los pobres más pobres (Asia Meridional y África) el enfoque financiero se orienta más bien a los micro, pequeños y medianos empresarios (América Latina y Oriente Medio/África del Norte). En este sentido, también se involucran los niveles de rendimiento perseguidos por las instituciones microfinancieras, donde buscan tener los menores costes y gastos para obtener un mayor rendimiento, pues en el caso del modelo social al enfocarse a los pobres más pobres siempre enfrentará costos altos en los créditos ofrecidos ya que generalmente las personas en situación de pobreza se encuentran ubicados en zonas alejadas y rurales que tienen unas infraestructuras de comunicación poco desarrolladas. 
El comportamiento de las cuatro regiones analizadas según los resultados de los diferentes indicadores ponen de manifiesto que existen diferencias regionales en cuanto al modelo dominante de microcrédito, más financiero o más social. Ello sin embargo no implica, en algunos casos, como el de Asia Meridional, que exista un trade-off entre los objetivos de sostenibilidad financiera y de alcance a las poblaciones más pobres, ya que en este caso se observa que en la práctica es posible obtener un equilibrio entre ambos enfoques, ya que esta región ha desarrollado un modelo que logra una alta sostenibilidad financiera sin tener que renunciar a servir mayoritariamente a las personas con un nivel elevado de pobreza. Pero a su vez en el resto de regiones el trade-off es más claro al observarse una tendencia muy marcada por uno de los dos modelo pudiéndose afirmar que existe en estas regiones existe una cierta incompatibilidad entre ambos enfoques tal y como se plantea a nivel teórico. América Latina y Oriente Medio/África del Norte se decantan por el objetivo de sostenibilidad financiera, siendo por lo tanto regiones altamente viables, debido a que recurren al uso de metodologías más próximas a las de la banca tradicional, lo que provoca que se vea amenazado el alcance a las poblaciones más pobres. En el caso de África, que demuestra una gran vocación y consecución del alcance a personas muy pobres, su sostenibilidad financiera se ve cuestionada por factores como la alta dependencia de subvenciones y por ser un sector en pleno desarrollo, por lo que todavía las estrategias de posicionamiento del servicio del microcrédito no han logrado obtener un buen desempeño financiero.

Los resultados también muestran como el papel de la mujer en el acceso al microcrédito es un factor que puede contribuir a disminuir los niveles de pobreza al ser las mujeres las principales prestatarias en el modelo social. Ello es evidente en el caso de Asia Meridional donde el acceso de la mujer al microcrédito es abrumador, el cual se explica por la metodología del Self Help Groups -grupos solidarios conformados únicamente por mujeresque muestran claramente que este acceso de la mujer además de su posible impacto en términos de desarrollo puede también tener altos estándares de sostenibilidad operativa y financiera. Así, a medida que el sector adquiere mayor sofisticación en el desarrollo de productos y servicios va cobrando un sentido social y financiero el prestar atención al enfoque de la mujer y de alguna u otra forma contribuir a su empoderamiento. En el caso de América Latina, igualmente debido a la metodología de préstamos individuales, se observa que se limita el acceso de la mujer al microcrédito, lo que lo convierte en un factor determinante para que el alcance de esta región no sea mayor. Por lo tanto, la dimensión específica de género en relación a los diferentes modelos regionales de microcrédito muestra como las diferentes 
metodologías de servicio de microcrédito conllevan patrones diferentes y modelos específicos de microcrédito. En este sentido, podemos afirmar que el microcrédito es también una herramienta que se adapta a las condiciones sociales y culturales de cada región, optando de algún modo por un modelo "a medida" teniendo en cuenta las circunstancias y condiciones locales.

Por último mencionar que son evidentes los retos que enfrenta el microcrédito, especialmente en términos de regulación, búsqueda de financiación, competencia, disminución de los costos y aumento de la rentabilidad y productividad. Pero sobre todo, el mayor de los desafíos representa atender a los millones de personas pobres y excluidas del sistema financiero tradicional, que aún no tienen acceso a ningún tipo de servicios financieros, para poder otorgarles una posibilidad de romper el círculo vicioso de la pobreza, y lograr mejorar su nivel de vida y el de sus familias. De ahí, la responsabilidad enorme del Estado, el sector privado y las entidades operadoras de microcrédito para que se logre desarrollar un portafolio de servicios innovador, con los instrumentos de medición adecuados y con tasas de interés razonables con el objetivo último de reducir la población en condiciones de pobreza y conseguir un mayor nivel de desarrollo socioeconómico de la población.

\section{BIBLIOGRAFÍA}

AGIER, I. y SZAFARZ, A. (2013) Microfinance and gender: Is there a glass ceiling on loan size?, World Development, vol. 42, pp. 165-181.

ARMENDÁRIZ, B. y Morduch J. (2007) The economics of microfinance, Massachusetts Institute of Technology, Cambridge, MIT Press, pp. 3-10.

AWAWORYI, A. y MARR, S. (2012) Microfinance social performance: a global empirical study, Applied Econometrics and International Development, 12 (2)

BANCO MUNDIAL (2011) Informe sobre desarrollo mundial 2012. Igualdad de género y desarrollo, Banco Internacional de Reconstrucción y Fomento/Banco Mundial, Washington, DC.

BANERJEE, A.J. et al (2013) The miracle of microfinance? Evidence from a randomized evaluation, MIT, Working paper No.13-09.

BID (2003) Methodological and practical considerations for constructing socio-economic indicators to evaluate disaster risk, Programa BID/IDEA de Indicadores para la Gestión de Riesgos, Universidad Nacional de Colombia, http://idea.unalmzl.edu.co (Fecha de consulta: Agosto 31 de 2012). 
BRAU, J. y WOLLER, G. (2004) Microfinance institutions: a comprehensive review of the existing literatura. Marriot School, Brigham Young University. Working paper No. 997.

CGAP (2005) Los Bancos Comerciales y las Microfinanzas: evolución de modelos que han dado buenos resultados, Enfoque Nro. 20, Washington, D.C., pp. 10-15.

CULL, R. et al (2006) Financial performance and outreach: a global analysis of leading microbanks, World Bank Policy Research, Working Paper 3827.

DUNFORD, Ch. (2000) The power of integration. Freedom from Hunger, http://www.freefromhunger.org/news/tier2/brief2.html (Fecha de consulta: Abril 2 de 2013).

DUNFORD, Ch. y DENMAN, V. (2001) Credit with education: a promising title II microfinance strategy, Food and Nutrition Technical Assistance (FANTA) Project. Academy for Educational Development, Freedom from Hunger. http://www.ffhtechnical.org (Fecha de consulta: Junio 21 de 2013).

EUROPEAN MICROFINANCE NETWORK (2010) Microcredit networks and existing national legislations with a view to the implementation of the microfinance instrument, Policy Department Economic and Scientific Policy. European Parliament. pp. 11-21.

GONZÁLEZ-VEGA C. (2002) Estrategia para la profundización de los mercados financieros rurales en los países andinos y del Caribe, Rural Finance, http://www.ruralfinance.org/servlet/, Fecha de consulta: Mayo 17 de 2013.

MAYOUX, L. (2000) Micro-finance and the empowerment of women: a review of the key issues, Social Finance Working. Paper No. 23.

MAYOUX, L. (2001) Micro-finance for women's empowerment: a participatory learning, management and action approache, Asia Regional Micro-credit Summit February 2000. UNIFEM.

MCCORD, M.J. y OSINDE S. (2005) Reducing vulnerability: the supply of health microinsurance in East Africa. Journal of International Development, vol. 17, pp. 327381.

MCNELLY, B. (1998) Impact of credit with education on mothers and their young children's nutrition: lower Pra Rural Bank credit with education program in Ghana, Research Paper No. 4. Freedom from Hunger.

MIX MARKET (2010) Eastern Europe and Central Asia Microfinance Analysis and Benchmarking Report 2010, http://www.themix.org/publications/mix-microfinanceworld/2011/03/eastern-europe-and-central-asia-microfinance-analysis-an (Fecha de consulta: junio 29 de 2012). 
MORDUCH, J. (1999) The microfinance promise. Journal of Economic Literature. Vol. XXXVII. pp. 1569-1614.

MORDUCH, J. (2000) The Microfinance Schism, Development Discussion Paper $\mathrm{n}^{\circ}$ 626, Institute for International Development, Harvard University, http://www.cid.harvard.edu/hiid/626.pdf (Fecha de consulta: Agosto 10 de 2012).

MORDUCH, J. (2002) Analysis of the effects of microfinance on poverty reduction, NYU Wagner Working Paper No. 1014, pp. 92-115.

MORDUCH, J., Cull, R. y Demirguc-Kunt, A. (2007) Financial performance and outreach: a global analysis of leading microbanks, Economic Journal, vol. 117, pp. 107-133.

NGO, T.M.-P. y WAHHAJ, Z. (2011) Microfinance and gender empowerment, Journal of Development Economics, 99 (1), pp. 1-12.

PITT, M.M. y KHANDKER, S. R. (1998) The impact of group-based credit programs on poor households in Bangladesh: Does the gender of participants matter, Journal of Political Enomomy, vol. 106, pp. 958-996.

PITT, M.M., KHANDKER, S.R. y CARTWRIGHT J. (2006) Empowering women with micro finance: evidence from Bangladesh, Economic Development and Cultural Change, vol. 54. pp. 791-831.

PITA, S. (1996) Complexo Hospitalario Juan Canalejo, Universidad de Alicante, pp. 25-27.

REED, L.R. (2011) Informe del estado de la campaña de la cumbre de microcréditos 2010, Microcredit Summit Campaign, Washington D.C.

VON PISCHKE, J.D. (2002) Rural financial markets in developing countries, Johns Hopkins University Press, pp. 118-125.

WOLLER, G., DUNFORD, Ch. y WOODWORTH, W. (1999) Where to microfinance?, International Journal of Economic Development, vol. 1, pp. 29-64.

WOLLER, G. y PARSONS, R. (2002) Assessing the community economic impact of microfinance institutions, Marriott School, Brigham Young University. Journal of Developmental Entrepreneurship, Nro. 7.

YUNUS, M. (2002) Grammen Bank at a glance, Grammen Bank, p. 12.

YUNUS, M. (2006) El Banquero de los Pobres. Los Microcréditos y la Batalla contra la Pobreza en el Mundo, Paidós, Barcelona. 